Abstract

\title{
The Biosemiotic Emergence of Referential Information ${ }^{\dagger}$
}

\author{
Terrence W. Deacon \\ Department of Anthropology, University of California, Berkeley, CA 94720, USA; deacon@berkeley.edu \\ + Presented at the IS4SI 2017 Summit DIGITALISATION FOR A SUSTAINABLE SOCIETY, Gothenburg, \\ Sweden, 12-16 June 2017.
}

Published: 9 June 2017

Although molecules like DNA can be analyzed in terms of their intrinsic information content on the basis of their structural complexity, it is their role in regulating cell metabolism and preserving genetic inheritance that is central. It is a basic tenet of cellular molecular biology that the sequence of nucleotides in a DNA polymer provides information contributing to the structure of proteins and their metabolic interactions and that DNA replication preserves and transmits this information across organism generations. In this respect one can describe DNA structures as being "about" protein structures and indirectly about cell function with respect to a probable environment. It is not merely that we as observers have made this referential assessment. It is intrinsic to cell function and evolution. But there is nothing intrinsic to nucleic acid polymers that makes them intrinsically referential. How a molecule like DNA or RNA could have acquired this property of being "about" other molecules and their interrelationships remains mysterious. In this presentation I will describe a molecular thought experiment that demonstrates how dynamical constraints embodied in a simple molecular system can become spontaneously offloaded onto a molecule's structural constraints such that this structure separately preserves and re-presents the dynamical constraints that are critical for reconstituting the containing molecular system should it become disrupted. Three variants on this model system provide unambiguous examples of three canonical referential relationships that roughly correspond to iconic, indexical, and symbolic referential relationships. This analysis can help to formalize the relationship between physical-chemical, informational, and semiotic theories of life, as well as provide clues to the origin and nature of molecular genetic information.

(C) 2017 by the author. Licensee MDPI, Basel, Switzerland. This article is an open access article distributed under the terms and conditions of the Creative Commons Attribution (CC BY) license (http://creativecommons.org/licenses/by/4.0/). 